\title{
Management of extra-pulmonary tuberculosis (excluding miliary and meningeal) in south and west Wales (1976-8)
}

\author{
R D H MONIE, A M HUNTER, K M S ROCCHICCIOLI, J P WHITE, I A CAMPBELL, \\ G S KILPATRICK
}

\begin{abstract}
In a retrospective survey of the management of extrapulmonary tuberculosis lymph node and genitourinary tuberculosis were found more commonly than bone and joint or gynaecological disease. Only $29 \%$ of patients received 18 months' chemotherapy while $31 \%$ received nine to 12 months' treatment with rifampicin and isoniazid regimens and $34 \%$ had short-course chemotherapy with other regimens. Five patients were not offered any chemotherapy after diagnosis, and in five patients the diagnosis was overlooked because of administrative errors. One patient died from tuberculosis (renal). Poor drug compliance appeared less of a problem than in pulmonary tuberculosis. Only $14 \%$ of patients had their disease managed solely by consultants who were not specialists in chest disease. Liaison with a chest consultant did not necessarily ensure chemotherapy for 18 months.
\end{abstract}

Welsh National School of Medicine, Llandough Hospital, Penarth, S Glamorgan CF6 1XX

R D H MONIE, MB, MRCP, lecturer in chest diseases

G S KILPATRICK, MD, FRCP, David Davies professor of tuberculosis and chest diseases

Department of Thoracic Medicine, Llandough Hospital, Penarth, S Glamorgan CF6 1XX

A M HUNTER, MB, MRCP, senior registrar (current appointment: consultant physician, York District Hospital, York)

K M S ROCCHICCIOLI, MB, MRCP, registrar (current appointment: research registrar, Wythenshawe Hospital, Manchester)

I P WHITE, MB, MRCP, registrar (current appointment: research fellow, Guy's Hospital, London)

I A CAMPBELL, MD, MRCP, consultant in thoracic medicine

\section{Introduction}

After the British Thoracic Association short-course chemotherapy trial it was possible to recommend nine months' treatment with rifampicin and isoniazid supplemented by an initial period of ethambutol as standard treatment for pulmonary tuberculosis. ${ }^{1}$ To date no such recommendation of short-course chemotherapy has been made for extra-pulmonary tuberculosis. To assess what chemotherapeutic regimens are being used, and the duration of treatment, we have carried out a retrospective survey of the management of extra-pulmonary tuberculosis in parts of the principality.

\section{Methods}

This paper is part of an overall survey of the management of 1000 cases of tuberculosis covering the three years from 1 January 1976 to 31 December 1978. The survey of pulmonary tuberculosis has been published. ${ }^{2}$ Patients with extra-pulmonary tuberculosis (excluding miliary and meningeal) were traced and information documented in a similar fashion, with an additional note of whether or not chemotherapy was supervised by a consultant with a special interest in chest diseases and tuberculosis. As case notes do not contain information about racial origin, the incidence of each ethnic group is based on the place of birth and the patient's name.

Poor drug compliance was registered if the physician supervising treatment recorded it in the patients' case notes or if the patient failed to attend clinic on two or more occasions without good reason.

\section{Results}

The case notes of 215 patients with extra-pulmonary tuberculosis during the three-year period were reviewed. The site of the disease, together with details of sex, age, and ethnic origin, is shown in table I. Table II shows the basis for diagnosis, and table III details of the treatment regimens. The regimens given to 35 patients could not be 
TABLE I-Patient details and incidence of extra-pulmonary tuberculosis

\begin{tabular}{|c|c|c|c|c|c|c|c|c|c|c|c|}
\hline \multirow[b]{2}{*}{ Site } & \multirow{2}{*}{$\begin{array}{c}\text { No of } \\
\text { patients }\end{array}$} & \multicolumn{2}{|c|}{ Sex } & \multicolumn{4}{|c|}{ Age (years) } & \multicolumn{2}{|c|}{ Ethnic group } & \multirow{2}{*}{$\begin{array}{l}\text { Percentage } \\
\text { of extra- } \\
\text { pulmonary } \\
\text { cases }\end{array}$} & \multirow{2}{*}{$\begin{array}{c}\text { Percentage } \\
\text { of all TB } \\
\text { cases }\end{array}$} \\
\hline & & Male & Female & $0-14$ & $15-44$ & $45-64$ & $\geqslant 65$ & European & $\begin{array}{c}\text { Non- } \\
\text { European }\end{array}$ & & \\
\hline $\begin{array}{l}\text { Lymph node } \\
\text { Genitourinary } \\
\text { Bone/ioint } \\
\text { Gynaecological } \\
\text { Other sites }\end{array}$ & $\begin{array}{l}82 \\
61 \\
29 \\
21 \\
22\end{array}$ & $\begin{array}{r}31 \\
43 \\
17 \\
0 \\
10\end{array}$ & $\begin{array}{l}51 \\
18 \\
12 \\
21 \\
12\end{array}$ & $\begin{array}{l}8 \\
0 \\
0 \\
0 \\
2\end{array}$ & $\begin{array}{r}32 \\
19 \\
7 \\
11 \\
8\end{array}$ & $\begin{array}{r}19 \\
28 \\
17 \\
10 \\
5\end{array}$ & $\begin{array}{r}23 \\
14 \\
5 \\
0 \\
7\end{array}$ & $\begin{array}{l}55 \\
61 \\
27 \\
21 \\
19\end{array}$ & $\begin{array}{r}27 \\
0 \\
2 \\
0 \\
3\end{array}$ & $\begin{array}{r}38 \cdot 1 \\
28 \cdot 4 \\
13 \cdot 5 \\
9.8 \\
10 \cdot 2\end{array}$ & $\begin{array}{l}8 \cdot 1 \\
6 \cdot 1 \\
3 \cdot 0 \\
2 \cdot 1 \\
2 \cdot 2\end{array}$ \\
\hline Totals & 215 & 101 & 114 & 10 & 77 & 79 & 49 & 183 & 32 & 100 & 21.5 \\
\hline
\end{tabular}

TABLE II-Basis for diagnosis and numbers never seen by a chest consultant

\begin{tabular}{|c|c|c|c|c|c|}
\hline \multirow{2}{*}{ Site } & \multirow{2}{*}{$\begin{array}{c}\text { No of } \\
\text { patients }\end{array}$} & \multicolumn{3}{|c|}{ Basis for diagnosis } & \multirow{2}{*}{$\begin{array}{l}\text { Not seen } \\
\text { by chest } \\
\text { consultant }\end{array}$} \\
\hline & & $\begin{array}{l}\text { Culture } \\
\text { positive }\end{array}$ & Histology & $\underset{x \text {-ray/TB test }}{\text { Clinical/ }}$ & \\
\hline $\begin{array}{l}\text { Lymph node } \\
\text { Genitourinary } \\
\text { Bone/joint } \\
\text { Gynaecological } \\
\text { Other sites }\end{array}$ & $\begin{array}{l}82 \\
61 \\
29 \\
21 \\
22\end{array}$ & $\begin{array}{r}42 \\
43 \\
13 \\
5 \\
11\end{array}$ & $\begin{array}{l}37 \\
13 \\
10 \\
16 \\
10\end{array}$ & $\begin{array}{l}3 \\
5 \\
6 \\
0 \\
1\end{array}$ & $\begin{array}{r}7 \\
15 \\
2 \\
2 \\
4\end{array}$ \\
\hline Totals & 215 & $114(53 \%)$ & $86(40 \%)$ & $15(7 \%)$ & $30(14 \%)$ \\
\hline
\end{tabular}

analysed because of inadequate records (5), deaths before completion of treatment (11), and poor drug compliance (19). Fifteen of the 19 patients who complied poorly with treatment were under the care of a chest physician. Seventeen patients received rifampicin-isoniazidethambutol, one streptomycin-ethambutol-rifampicin and one refused any treatment. Five patients experienced side effects to their drugs. Eight patients defaulted from follow-up less than six months after starting treatment, and another two patients subsequently received supervised treatment in hospital.

\section{LYMPH NODE TUBERCULOSIS}

Eighty-two patients had lymph node tuberculosis. Female patients outnumbered male patients by five to three, and a third were nonEuropean. Cases were fairly evenly spread through the age range. European female patients were older while the younger ones tended to be non-European. Three patients were diagnosed on clinical grounds: two had previously had glandular tuberculosis and were presumed to have relapsed, and one, an Asian, was newly diagnosed (table II).

Four patients $(5 \%)$ were not prescribed any treatment and in 16 patients the regimen was not analysed (table III). Of the remaining 62 patients, $21(33 \%)$ received 18 months' chemotherapy. One patient was given only eight months' treatment, and another patient's treatment was stopped after one month because of jaundice and was never restarted.

\section{GENITOURINARY TUBERCULOSIS}

Sixty-one patients had genitourinary tuberculosis. The genital tract was affected clinically in 12 out of the 43 male patients. All patients were European. Seven were diagnosed after nephrectomy, eight after orchidectomy, and one each after testicular biopsy and prostatectomy. After starting chemotherapy a further six patients had a nephrectomy performed because of a non-functioning kidney, and four required reconstructive surgery to ureters or bladder.

Four patients were not prescribed any treatment, and in seven the regimen was not analysed (table III). Of the remaining 50 patients, only $14(28 \%)$ received 18 months' chemotherapy. One patient, although receiving 15 months' chemotherapy, had aminosalicylic acid (PAS) alone for 14 months.

\section{BONE AND JOINT TUBERCULOSIS}

Twenty-nine patients had bone and joint tuberculosis. There were no sex differences and most were aged between 45 and 64 . Only two were non-European. Ten patients had involvement of the spine, six of the hip, three the shoulder, and the remainder elbow, wrist, ankle, and ribs. Six $(20 \%)$ were diagnosed on clinical grounds and $x$-ray appearances, one of these patients having a negative tuberculin test.

In five the treatment was not analysed, and of the remaining 24 only nine $(38 \%)$ received 18 months' therapy (table III).

\section{GYNAECOLOGICAL TUBERCULOSIS}

Twenty-one women had gynaecological tuberculosis. All were European. In two patients no treatment was prescribed, and in two the regimen was not analysed. Only four of the remaining 17 patients had treatment for 18 months (table III).

\section{OTHER SITES}

Twenty-two patients had other sites affected: 11 with subcutaneous cold abscesses, five intra-abdominal tuberculosis, two with lupus

TABLE III-Treatment regimens (duration in months) given by chest and non-chest consultants. (35 regimens were not analysed due to: inadequate records (5), poor drug compliance (19), and deaths (11))

\begin{tabular}{|c|c|c|c|c|c|c|c|c|c|c|c|}
\hline \multirow{2}{*}{ Site } & \multirow{2}{*}{$\begin{array}{c}\text { No of } \\
\text { patients }\end{array}$} & \multirow{2}{*}{$\begin{array}{c}\text { EHR/HR } \\
\text { SHR/HR or } \\
\text { EHR/EHR }\end{array}$} & \multirow{2}{*}{$\underset{\substack{\mathrm{RHE} / \mathrm{HE} \text { or } \\
\mathrm{SHE} / \mathrm{HE}}}{ }$} & \multirow{2}{*}{$\begin{array}{c}\text { HRE/RE or } \\
\text { SRE/RE }\end{array}$} & \multicolumn{3}{|c|}{ Two drugs } & \multirow{2}{*}{\multicolumn{2}{|c|}{$\begin{array}{l}\text { Other regimens given } \\
\text { to single patients } \\
\text { (duration in months) }\end{array}$}} & \multirow{2}{*}{$\begin{array}{l}\text { No } \\
\text { drug } \\
\text { treatment }\end{array}$} & \multirow{2}{*}{$\begin{array}{c}\text { Regimen } \\
\text { not } \\
\text { analysed }\end{array}$} \\
\hline & & & & & HR & $\mathrm{HE}$ & RE & & & & \\
\hline \multirow{2}{*}{ Lymph node } & \multirow{2}{*}{82} & \multirow{2}{*}{$\begin{array}{l}12(9-12) \\
7(13-17) \\
9(\geqslant 18)\end{array}$} & \multirow{2}{*}{$\begin{array}{l}3(9-12) \\
2(13-17) \\
7(\geqslant 18)\end{array}$} & & $6(9-12)$ & \multirow{2}{*}{$\begin{array}{l}3(9-12) \\
1(13-17) \\
2(\geqslant 18)\end{array}$} & \multirow[t]{2}{*}{$1(9-12)$} & $\begin{array}{l}\text { EHR } \\
\mathrm{PHR} / \mathrm{HR}\end{array}$ & $\begin{array}{l}(1) \\
(18)\end{array}$ & \multirow{2}{*}{4} & \multirow{2}{*}{16} \\
\hline & & & & $1(\geqslant 18)$ & $1(\geqslant 18)$ & & & $\begin{array}{l}\mathrm{HR} \\
\mathrm{EH} \\
\mathrm{SH} / \mathrm{HR}\end{array}$ & $\begin{array}{r}(8) \\
(1) \\
(18)\end{array}$ & & \\
\hline Genitourinary & 61 & \multirow{4}{*}{$\begin{array}{c}18(9-12) \\
8(13-17) \\
10(\geqslant 18) \\
11(9-12) \\
2(13-17) \\
6(\geqslant 18) \\
8(9-12) \\
1(13-17) \\
4(\geqslant 18) \\
7(9-12) \\
2(13-17) \\
2(\geqslant 18)\end{array}$} & $\begin{array}{l}2(9-12) \\
2(\geqslant 18)\end{array}$ & \multirow[t]{4}{*}{$1(13-17)$} & \multirow{3}{*}{$2(9-12)$} & \multirow[t]{4}{*}{$2(9-12)$} & \multirow[t]{4}{*}{$\begin{array}{l}1(9-12) \\
1(13-17)\end{array}$} & $\begin{array}{l}\text { PHR/HR } \\
\text { SP/P } \\
\text { SPHE/PHE } \\
\text { PH }\end{array}$ & $\begin{array}{r}(9) \\
(15) \\
(23) \\
(6)\end{array}$ & 4 & 7 \\
\hline Bone/joint & 29 & & \multirow[t]{2}{*}{$\begin{array}{l}2(1 \geqslant 8) \\
1(9-12)\end{array}$} & & & & & $\begin{array}{l}\text { PH } \\
\text { SRHE/HE } \\
\text { SPH/PH }\end{array}$ & $\begin{array}{l}(16) \\
(13) \\
(21)\end{array}$ & \multirow{3}{*}{2} & \multirow{3}{*}{2} \\
\hline Gynaecological & 21 & & & & & & & EZHR/HR & (13) & & \\
\hline Other sites & 22 & & $1(13-17)$ & & $\begin{array}{l}2(9-12) \\
1(13-17) \\
1(\geqslant 18)\end{array}$ & & & $\mathrm{EZ}$ & (10) & & \\
\hline Totals & 215 & $\begin{array}{l}56(9-12) \\
20(13-17) \\
31(\geqslant 18)\end{array}$ & $\begin{array}{c}6(9-12) \\
3(13-17) \\
11(\geqslant 18)\end{array}$ & $\begin{array}{l}3(9-12) \\
1(13-17) \\
1(\geqslant 18)\end{array}$ & $\begin{aligned} 10 & (9-12) \\
1 & (13-17) \\
2 & (\geqslant 18)\end{aligned}$ & $\begin{array}{l}5(9-12) \\
1(13-17) \\
2(\geqslant 18)\end{array}$ & $\begin{array}{l}2(9-12) \\
1(13-17)\end{array}$ & 14 & & 10 & 35 \\
\hline
\end{tabular}


vulgaris, and one each with pericardial, nasal, parotid, and splenic involvement. Five of the 11 cases with subcutaneous cold abscesses were on the chest wall, two on the foot, and one each related to breast, buttock, and calf muscle, with one site unknown.

Three patients were non-European. The patient with constrictive pericarditis was diagnosed on clinical grounds and a positive tuberculin test. Three of the five patients with abdominal infection were aged 14,15 , and 18 years.

In five patients the regimens were not analysed, and of the remaining 17 patients only three received 18 months' chemotherapy (table III).

\section{NO CHEMOTHERAPY}

Overall, 10 patients $(6 \%)$ were offered no chemotherapy. In five this was because of administrative errors. In the other five $(3 \%)$ a decision was made not to give any chemotherapy; in three no bacilli were seen on histological examination and the tuberculosis was deemed inactive, although no tissue was sent for culture; in one the consultant thought that the tuberculosis had been treated surgically, and in one the infection was considered to be quiescent despite positive cultures. Chest consultants were not concerned in these decisions.

CHEMOTHERAPY ORGANISED SOLELY BY CONSULTANTS WHO WERE NOT SPECIALISTS IN CHEST DISEASES

In a further 20 patients $(11 \%)$ there was no consultation with a chest consultant about anti-tuberculous regimens (table IV), 11 of these having genitourinary tuberculosis.

TABLE IV-20 treatment regimens used by non-chest consultants

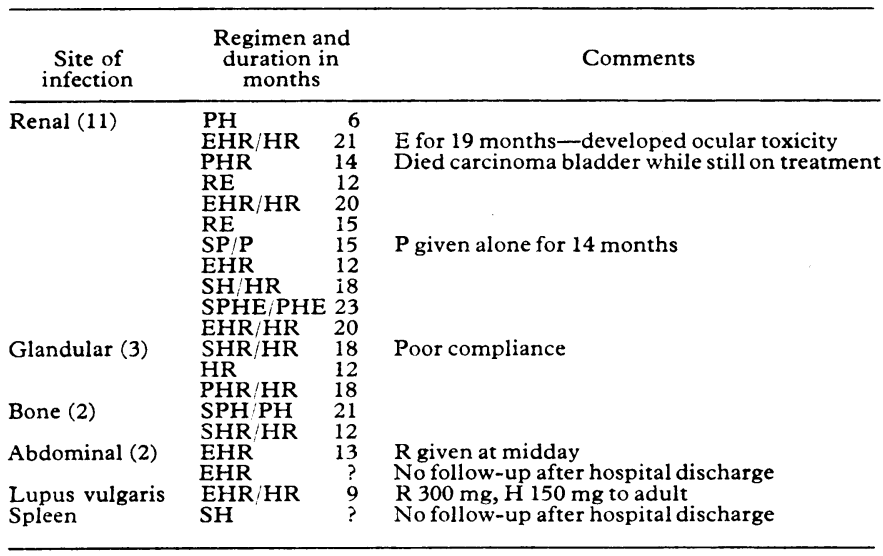

$\mathrm{P}=$ Aminosalicylic acid. $\mathrm{H}=$ Isoniazid. $\mathrm{E}=$ Ethambutol. $\mathrm{R}=$ Rifampicin.

\section{DEATHS}

Eleven patients died, but only one was considered to be due to tuberculosis. This patient died from progressive renal failure and at necropsy was found to have renal tuberculosis.

\section{RELAPSES}

To date only one patient who received chemotherapy is known to have relapsed. This patient had glandular tuberculosis with positive cultures but received under one month's chemotherapy because of side effects, and relapsed with positive cultures. Two patients who were not given any chemotherapy have had further symptoms and received treatment: in one after orchidectomy, but results of urine culture from two years previously had been positive and were overlooked; and in the other lymph node tuberculosis was treated two years after positive cultures were first obtained.

\section{SIDE EFFECTS}

Twenty-four patients $(13 \%)$ had side effects from their treatment. Sixteen $(9 \%)$ continued having the same treatment after a brief interruption or after desensitisation. Treatment was altered in eight $(4 \%)$, two of whom had their treatment stopped after less than a month and never restarted. Two patients taking the contraceptive pill became pregnant while taking rifampicin. Isoniazid side effects were rashes (1), fever (1), and peripheral neuropathy (5). Three patients complained of visual disturbances when taking ethambutol, but only one had reduced visual acuity (this patient had received $15 \mathrm{mg} / \mathrm{kg}$ body weight for 19 months) which reversed on stopping the drug. Two out of six patients taking aminosalicylic acid had gastrointestinal disturbances. One patient had nausea that cleared on stopping pyrazinamide. Nine patients had drug rashes, fevers, jaundice, or gastrointestinal upset, it was not clear which drug was implicated. Rifampicin was discontinued in one further patient solely because of a rise in liver transaminases.

\section{Discussion}

Out of 215 patients with extra-pulmonary tuberculosis the management of 180 could be analysed, the other 35 being excluded (table III). Despite the lack of any properly controlled trial of short-course chemotherapy for extra-pulmonary tuberculosis, 56 patients $(31 \%)$ were given nine to 12 months of ethambutol-isoniazid-rifampicin/isoniazid-rifampicin (EHR/ HR) or streptomycin-isoniazid-rifampicin/isoniazid-rifampicin (SHR/HR) treatment, the regimen most like that recommended for short-course chemotherapy for pulmonary tuberculosis. A further 63 patients $(35 \%)$ received other regimens for under 18 months. Only 51 patients $(28 \%)$ received 18 months' chemotherapy. In our report of the treatment of pulmonary tuberculosis there appeared to be some reluctance among chest consultants to follow the recommendations for short-course chemotherapy based on clinical trial results, $29 \%$ of patients receiving ethambutol-isoniazid-rifampicin/isoniazid-rifampicin or streptomycin-isoniazid-rifampicin/isoniazid-rifampicin for longer than was necessary. ${ }^{2}$ It seems paradoxical that in extra-pulmonary infection, where no properly controlled trial of short-course chemotherapy has been reported, more patients received shortcourse regimens than the standard 18 months' regimen.

Crofton $^{3}$ and Sutherland ${ }^{4}$ recommend that chemotherapy for extra-pulmonary tuberculosis should be supervised by a chest consultant. A chest consultant was not concerned in the management of 30 patients. In five, despite positive cultures, antituberculous chemotherapy was not given because of administrative errors. These errors were caused by results being filed in the patients' case notes without a doctor seeing them in three, and letters of referral to a chest physician going astray in two. In the remaining 25 patients $(14 \%)$ the tuberculous disease was managed by consultants who were not specialists in chest diseases without advice from a chest consultant. Among the five patients who were offered no chemotherapy this decision was made in three on the grounds that no bacilli were seen histologically. In the other two patients no chemotherapy was offered because the disease was considered to be inactive in one despite positive cultures, and surgery alone was considered curative in the other. Urologists alone supervised chemotherapy in $22 \%$ of patients with genitourinary tuberculosis (table IV), but none used any of the regimens recommended by Gow. ${ }^{5}$ Some of the regimens prescribed by non-chest consultants would be considered inadequate (table IV) with errors of duration of treatment and dosages of drugs as found by Wardman et al. ${ }^{6}$ Some of the regimens supervised by chest consultants, although using correct dosages, were inadequate in their duration (table III). A similar proportion of patients received 18 months' chemotherapy, whether supervision was by a chest consultant $(29 \%)$ or a nonchest consultant $(28 \%)$.

Eighty-six patients were diagnosed on histological grounds, but in only eleven $(13 \%)$ was there any evidence that tissue had been sent for culture. Three patients were not offered any chemotherapy on grounds that no bacilli were seen histologically, although no tissue was sent for culture.

As previously noted ${ }^{78}$ lymph node tuberculosis was the most common extra-pulmonary manifestation. One-third of the 
patients were non-European, a figure lower than in previous reports, but only $2 \%$ of the population of the area surveyed were non-European ${ }^{9}$ compared with $4 \%$ from England. ${ }^{8}$ Lymph node tuberculosis was more common in female patients as noted before, ${ }^{1011}$ the European female patients tending to be older (12 over 75) while the non-Europeans more often presented between 20 and 40, a confirmation of previous findings. ${ }^{11}$ The disease in elderly Europeans may be related to first-time infection (unlikely), a breakdown of disease acquired and limited years previously, or re-infection behaving as primary disease because of an age-related change in immune status.

Genitourinary and gynaecological tuberculosis appeared to be more common sites for infection in our study than in the National Survey of Tuberculosis Notifications. ${ }^{8}$ The reason for our apparently increased incidence, as compared with the notification study, lies in the failure to notify: one-third of the patients with genitourinary tuberculosis did not appear on the notification lists. Genitourinary and gynaecological tuberculosis was predominantly seen in the white ethnic group, as noted in a previous study. ${ }^{12}$

Bad compliance was recorded in 19 patients (9\%) compared with $12 \%$ in our pulmonary survey. This difference may be because $53 \%$ of patients with extra-pulmonary disease were female compared with only $18 \%$ in the pulmonary survey. No patients with gynaecological tuberculosis failed to comply with treatment. Eleven patients died, but only one death $(<0.5 \%)$ was considered to be attributable to tuberculosis compared with $5 \%$ of patients who died from their pulmonary tuberculosis.

Despite the use of regimens that many would regard as inadequate, we know of only one relapse after chemotherapy. Relapse was assessed from the case notes (reviewed during 1979-80) and also with the help of the Mycobacterium Reference Laboratory in Cardiff, where no further positive cultures, to date, have been received from any of these patients. We recognise, however, the limitations of a retrospective survey such as this one when it comes to assessing the true incidence of relapse.

This study does highlight a cavalier tendency among doctors in respect to the management of extra-pulmonary tuberculosis, with a failure to take note of laboratory results (leading to orchidectomy in one patient). It suggests that female patients comply better with treatment, and makes the point that extrapulmonary disease (excluding miliary and meningeal) is not as lethal as pulmonary tuberculosis can be.

We thank the many physicians and surgeons who allowed us access to the case notes of patients in their care; the medical records staff in the areas; the medical officers for environmental health, the Welsh Office, and Dr P A Jenkins of the Mycobacterium Reference Laboratory, Cardiff, for helping us to trace the cases of tuberculosis; and Mrs K H Chaloner, Mrs P Davies, and Mrs C M Rowe for their secretarial help.

\section{References}

${ }^{1}$ A controlled trial by the British Thoracic and Tuberculosis Association. Short course chemotherapy in pulmonary tuberculosis. Lancet 1976;ii: 1102-4.

2 Monie RDH, Hunter AM, Rocchiccioli K, White J, Campbell IA, Kilpatrick GS. A retrospective survey of the management of pulmonary tuberculosis in south and west Wales 1976-8. Br Med f 1982;284:571-3.

${ }^{3}$ Crofton JW. Treatment of tuberculosis. Br Med f 1979;i:52.

4 Sutherland AM. Gynaecological tuberculosis. Br f Hosp Med 1979;22. 569-76.

${ }^{5}$ Gow JG. Genito-urinary tuberculosis. Br F Hosp Med 1979;22:556-68.

6 Wardman AG, Williams SE, Curzon PGD, Page RL, Cooke NJ. Tuberculosis: who should prescribe? Br Med f 1982;284:569-71.

7 British Tuberculosis Association. Tuberculosis among immigrants to England and Wales. A national survey in 1965. Tubercle 1966;47:145-56.

${ }^{8}$ Medical Research Council Tuberculosis and Chest Diseases Unit. National survey of tuberculosis notifications in England and Wales 1978-9. Br Med F 1980;281:895-8.

${ }^{9}$ Office of Population Censuses and Surveys. 1971 Census. London: OPCS, Small Area Statistics 1973-4.

10 Campbell IA, Dyson AJ. Lymph node tuberculosis: A comparison of various methods of treatment. Tubercle 1977;58:171-9.

11 Summers GD, McNichol MW. Tuberculosis of superficial lymph nodes. Br $\mathcal{F}$ Dis Chest 1980;74:369-73.

12 British Thoracic and Tuberculosis Association. A tuberculosis survey in England and Wales 1971: the influence of immigration and country of birth upon notifications. Tubercle 1973;54:249-60.

(Accepted 17 May 1982)
A 25-year-old patient is convinced that she ovulates from her right ovary one month, and from the left ovary the next, in a constant pattern. She tells me that alternate menstrual periods are either pain-free or very painful indeed. Is this possible, and if so is any treatment advised?

Although the side of ovulation may now be detected by ultrasound, long-term studies on individual women have not yet been published. One study ${ }^{1}$ included five women examined in two consecutive cycles: three of the women ovulated from the same ovary in consecutive months and the other two showed alternate ovarian activity. Ultrasound scans have confirmed that multiple follicles develop in both ovaries early in the cycle, and one of these becomes dominant and goes on to ovulate: the selection of the dominant follicle seems to be random. The usefulness of pain as an indicator of ovulation depends on when in the cycle the pain occurs. Dysmenorrhoea seems to be associated only with ovulatory cycles-probably because production of prostaglandin is greater in secretory than in proliferative endometrium. ${ }^{2}$ It seems most unlikely, however, that dysmenorrhoea would indicate which of two intact ovaries had ovulated. By contrast, mid-cycle pain (which occurs just before ovulation ${ }^{34}$ ) is often localised to one or other iliac fossa, which usually corresponds to the side of ovulation. ${ }^{3}$ The treatment of this patient depends on whether or not she wants to become pregnant. If she does, mid-cycle pain may be treated with analgesia only, and dysmenorrhoea with prostaglandin synthetase inhibitors such as mefenamic acid. If she does not desire pregnancy the first line of treatment would be oral contraceptives, unless these are contraindicated for other reasons.-J O DRIFE, lecturer in obstetrics and gynaecology, Bristol. 'Queenan JT, O'Brien GD, Bains LM, Simpson J, Collins WP, Campbell S,
Ultrasound scanning of ovaries to detect ovulation in women. Fertil Steril $1980 ; 34: 99-105$.
2 Pickles VR, Hall WJ, Best FA, Smith GN. Prostaglandins in endometrium and menstrual fluid from normal and dysmenorrhoeic subjects. Fournal of Obstetrics and Gynaecology of the British Commonwealth 1965;72:185-92.

${ }^{3} \mathrm{O}$ 'Herlihy C, Robinson HP, De Crespigny LJC. Mittelschmerz is a preovulatory symptom. Br Med $\mathcal{F} 1980 ; \mathbf{2 8 0}: 986$.

- Kerin JF, Edmonds DK, Warnes GM, et al. Morphological and functional relations of graafian follicle growth to ovulation in women using ultrasonic, 81-90.

I was asked to examine a 14-year-old girl, who was alleged to be having sexual intercourse, to determine whether she was a virgin. The vagina easily admitted a speculum and there was a vestigial hymen. How can an examining doctor be certain that such a finding is due to intercourse rather than to the regular use of tampons?

In one series ${ }^{1}$ of virgins (aged 15-48 with an average age of 20) vaginal examination could confirm virginity in only $60 \%$ of cases. Among the remaining $40 \%$ the vaginal introitus was sufficiently distensible to suggest to the examiner that intercourse had, or might have, occurred. This distensibility may be due to the use of tampons but is more probably due to biological variation. Recent sexual assault may leave evidence of trauma, and a small hymeneal opening is definite evidence of virginity, but it is impossible to prove by examination that a distensible introitus is the result of past intercourse. The previous tendency to doubt the word of such women is regrettable and the above findings now seem to have been accepted by the president of the family division of the courts. - JAMES OWEN DRIFE, lecturer in gynaecology, Bristol.

${ }^{1}$ Underhill RA, Dewhurst J. The doctor cannot always tell: medical examination of the "intact" hymen. Lancet 1978:i ;375-6. 